\title{
ANALISIS FISIK PENGARUH LIMBAH ABU AMPAS TEBU SEBAGAI SUBSTITUSI PARSIAL PADA BETON NORMAL
}

\author{
Fausiah Latif', Fauzan Hamdi ${ }^{2}$, Muh. Amir ${ }^{3}$ \\ IProgram Studi Teknik Pengairan, Universitas Muhammadiyah Makassar \\ Email:fausiah_latif@unismuh.ac.id \\ ${ }^{2}$ Program Studi Teknik Pengairan, Universitas Muhammadiyah Makassar \\ Email :fauzanhamdiunismuh@gmail.com \\ ${ }^{3}$ Program Studi Teknik Pengairan, Universitas Muhammadiyah Makassar \\ Email:Amirzainuddin20@yahoo.co.id
}

\begin{abstract}
Abstrak
Salah satu tantangan yang dihadapi para ahli teknologi beton adalah bagaimana memanfaatkan limbah industri sebagai bahan tambah atau substitusi parsial pada beton normal. Dalam hal ini, para ahli mengkaji dan meneliti tentang pemanfaatan limbah industri yang ada agar dapat dimanfaatkan terutama bahan limbah abu ampas tebu industri pabrik gula. Hal ini menjadi salah satu dari sekian solusi penanganan limbah yang ada dimasyarakat. Tujuan dari penelitian ini adalah untuk mengetahui pengaruh substitusi abu ampas tebu terhadap agregat halus pada beton normal secara fisik dan mekanik. Bahan yang digunakan dalam penelitian ini terdiri dari semen Portland Composit Cement (PCC), agregat halus Sungai Je'ne'berang Gowa, agregat kasar yang berasal dari batu pecah Bili-Bili dan air PDAM dan material limbah abu ampas tebu sebagai substitusi agregat halus berasal dari Pabrik Gula Kabupaten Takalar, Provinsi Sulawesi Selatan. Alat yang digunakan pada penelitian ini sebelumnya telah diperiksa kondisi dan kemampuannya serta telah dikalibrasi terlebih dahulu. Benda uji silinder dibuat dengan cara memasukkan beton segar dari molen ke dalam cetakan silinder ukuran $15 \mathrm{~cm}$ x $30 \mathrm{~cm}$ yang telah diolesi minyak pelumas. Pengisian ini dilakukan secara bertahap, yaitu tiap sepertiga bagian dilakukan penumbukan dengan tongkat baja sebanyak \pm 25 kali. Setelah 24 jam, cetakan dibuka kemudian dilakukan perawatan dengan direndam di dalam bak air selama 28 hari. Benda uji beton normal sebanyak 9 sampel dan benda uji yang disubstitusi abu ampas tebu sebanyak 9 sampel. Berdasarkan hasil penelitian didapatkan nilai berat volume beton untuk komposisi pencampuran ampas tebu $8 \%$ yaitu $701,41 \mathrm{~kg} / \mathrm{m} 3,10 \%$ yaitu $701,41 \mathrm{~kg} / \mathrm{m} 3$ dan $12 \%$ yaitu 690,10 $\mathrm{kg} / \mathrm{m} 3$ dari ketiga komposisi tersebut diperoleh berat volume beton yang maksimal yaitu komposisi pencampuran ampas tebu $12 \%$.
\end{abstract}

Kata Kunci : Beton Normal, Abu Ampas Tebu, dan Fisik

\begin{abstract}
One of the challenges faced by concrete technology experts is how to use industrial waste as an additive or partial substitution in normal concrete. In this case, the experts study and research about the use of existing industrial waste so that it can be utilized, especially the sugar cane bagasse ash waste material for the sugar factory industry. This is one of the many waste management solutions that exist in the community. The purpose of this study was to determine the effect of bagasse ash substitution on fine aggregate in normal physical and mechanical concrete. The materials used in this study consisted of Portland Composite Cement (PCC) cement, fine aggregate of the Je'ne'berang Gowa River, coarse aggregate originating from Bili-Bili crushed stone and PDAM water and bagasse ash as a substitute for fine aggregate originating from from the Sugar Factory of Takalar Regency, South Sulawesi Province. The tools used in this study had previously been checked for their conditions and capabilities and had been calibrated first. Cylindrical specimens are made by inserting fresh concrete from molen into a $15 \mathrm{~cm} \times 30 \mathrm{~cm}$ cylinder mold that has been smeared with
\end{abstract}


lubricating oil. This filling is carried out in stages, that is, for each third of the part, it is hit with a steel rod for \pm 25 times. After 24 hours, the mold was opened and then treated by being immersed in a water bath for 28 days. 9 samples of normal concrete samples and 9 samples of specimens substituted for bagasse ash. Based on the results of the research, it was found that the value of the volume weight of concrete for the composition of mixing bagasse $8 \%$, namely $701.41 \mathrm{~kg} / \mathrm{m} 3,10 \%$, namely 701.41 $\mathrm{kg} / \mathrm{m} 3$ and $12 \%$, namely $690.10 \mathrm{~kg} / \mathrm{m} 3$ from the three compositions, the weight of the concrete volume was obtained. the maximum is the composition of the bagasse mixing $12 \%$.

Keywords: Normal Concrete, Bagasse Ash, and Physical

\section{PENDAHULUAN}

Salah satu tantangan yang dihadapi para ahli teknologi beton adalah bagaimana memanfaatkan limbah industri sebagai bahan tambah atau substitusi parsial pada beton normal. Dalam hal ini, para ahli mengkaji dan meneliti tentang pemanfaatan limbah industri yang ada agar dapat dimanfaatkan terutama bahan limbah abu ampas tebu industri pabrik gula. Hal ini menjadi salah satu dari sekian solusi penanganan limbah yang ada dimasyarakat.

Untuk menjawab secara ilmiah tantangan tersebut sekaligus membantu masyarakat dalam menangani masalah ini secara tepat, maka kami selaku peneliti akan manganalisis serta mengembangkan teknologi ini agar dapat bermanfaat bagi basyarakat luas terutama dikalangan pengguna beton normal untuk struktur bangunan dan industri yang memproduksi limbah, dikhususkan limbah abu ampas tebu yang dihasilkan dari produksi gula. Tujuan dari penelitian ini adalah untuk mengetahui pengaruh substitusi abu ampas tebu terhadap agregat halus pada beton normal secara fisik.

\section{TINJAUAN PUSTAKA \\ Beton Normal}

Beton terdiri atas agregat, semen dan air yang dicampur bersama-sama dalam keadaan plastis dan mudah untuk dikerjakan. Karena sifat ini menyebabkan beton mudah untuk dibentuk sesuai dengan keinginan pengguna. Sesaat setelah pencampuran, pada adukan terjadi reaksi kimia yang pada umumnya bersifat hidrasi dan menghasilkan suatu pengerasan dan pertambahan kekuatan.

Mulyono (2006), mengungkapkan bahwa beton merupakan fungsi dari bahan penyusunnya yang terdiri dari bahan semen hidrolik, agregat kasar, agregat halus, air, dan bahan tambah. Sedang Sagel dkk. (1994), menguraikan bahwa beton adalah suatu komposit dari bahan batuan yang direkatkan oleh bahan ikat. Sifat beton dipengaruhi oleh bahan pembentuknya serta cara pengerjaannya. Semen mempengaruhi kecepatan 
pengerasan beton. Selanjutnya kadar lumpur, kebersihan, dan gradasi agregat mempengaruhi kekuatan pengerjaan yang mencakup cara penuangan, pemadatan dan perawatan, yang pada akhirnya mempengaruhi kekuatan beton.

Kekuatan beton terutama dipengaruhi oleh banyaknya air dan semen yang digunakan atau tergantung pada faktor air semen dan derajat kekompakannya. Adapun faktor yang mempengaruhi kekuatan beton adalah perbandingan berat air dan semen, tipe dan gradasi agregat, kualitas semen, dan perawatan (curing).

\section{Beton Substitusi Parsial Abu Ampas}

\section{Tebu}

M. Fahryan Azis (2020), setelah dilakukan uji kuat tekan beton, maka kuat tekan beton karakteristik pada umur 28 hari dengan kondisi normal sebesar 310,04 $\mathrm{kg} / \mathrm{cm} 2$, dan nilai kuat tekan karakteristik optimum terdapat di beton normal+Abu Ampas Tebu 5\%+ Abu Cangkang Sawit $5 \%$ sebesar 316,06 kg/cm2. Hasil tersebut melebihi nilai kuat tekan karakteristik beton normal dan menunjukan bahwa $\mathrm{Abu}$ Ampas Tebu dan Abu Cangkang Sawit meningkatkan kuat tekan beton.

as tebu dan superplasticizer dengan agregat batu pecah terhadap kuat tekan beton mengalami kenaikan, yaitu pada kandungan abu ampas tebu $15 \%$ dan
Prabowo Doro Djatun (2019), pengaruh penambahan abu tebu pada campuran beton sebagai aditif semen untuk kualitas beton k-300 dari hasil penelitian yang dilakukan di laboratorium beton PT. Perkasa Adiguna Sembada, hasil uji kuat tekan maksimum beton normal ditambah abu tebu $8 \%$ dari jumlah semen dengan nilai $319,15 \mathrm{Kg} / \mathrm{Cm} 2$.

Fatah Sulaiman (2019), prosedur awal dari penelitian dimulai dari preparasi abu ampas tebu dengan cara dibakar untuk mendapatkan kandungan SiO2, melakukan uji lengket abu ampas tebu dengan semen, pelaksanaan pembuatan beton dengan mencampurkan bahan-bahan berupa pasir, semen, batu kerikil, air, abu ampas tebu dan lateks, beton yang didapat diuji kuat tekannya. Kondisi optimum terdapat pada campuran lateks $10 \%$ dan abu ampas tebu 10\% dengan nilai kuat tekan 23,00 Mpa. Nilai kuat tekan tersebut mengacu pada SNI 03-1974-1990 kualitas K-277 dimana beton termasuk dalam beton normal struktural untuk aplikasi pembangunan dua lantai.

Tisnawati dan Dwi Kumalasari (2019), Pengaruh penambahan abu amp superplasticizer $1,5 \%$ dengan kuat tekan rata-rata sebesar 34,991 Mpa, jadi dengan penambahan abu ampas tebu telah mencapai nilai optimal dan hasil 
pemeriksaan terhadap penyerapan air pada abu ampas tebu didapatkan sebesar $10,57 \%$.

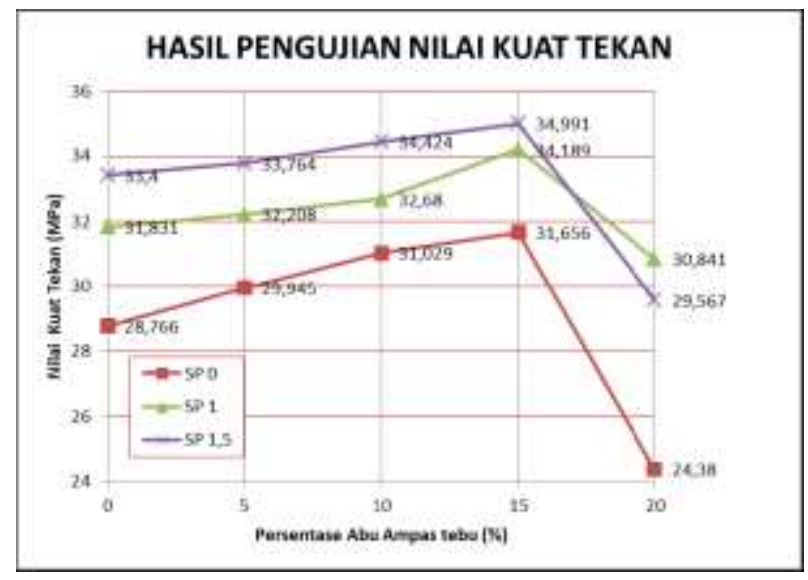

Gambar 1. Grafik Kuat Tekan Beton Tisnawati dan Dwi Kumalasari (2019)

Herri Mahyar, Rizal Syahyadi, Khairul Miswar (2018), hasil dari penelitian ini, secara umum dapat dinyatakan bahwa beton mutu tinggi yang menggunakan abu sekam padi dan abu ampas tebu dengan variasi substitusi semen $5 \%$, hasilnya lebih baik dari variasi substitusi semen $10 \%, 15 \%$ dan $0 \%$ (kondisi normal) terhadap sifat karakterisik beton mutu tinggi yaitu kuat tekan dengan nilai kuat tekan beton 53,77 MPa (3,78\%).

\section{Steven ATM Rajagukguk dan} Nursyamsi (2017), kuat tekan maksimum didapat pada beton dengan tambahan abu ampas tebu sebesar 5\% yaitu sebesar 26,76 Mpa.

Adi Wiyono, Adjib Karjanto dan Galih Damar Pandulu (2017), hasil penelitian menunjukkan bahwa penyerapan air yang paling rendah pada variasi campuran $8 \%$ dengan hasil rata-rata 1,54\% dan kuat tekan mortar yang paling besar terdapat pada $8 \%$ dengan kuat tekan rata-rata 25,04 Mpa.

Shinta Rahmalia Irawan (2014), dalam penelitian ini digunakan 3 kombinasi Abu Ampas Tebu (AT) dan Abu Kulit Kerang (CK) sebagai substitusi semen yaitu kombinasi (1) 8\% AT + 14\%CK; kombinasi (2) 10\%AT + 12\%CK; kombinasi (3) $12 \%$ AT $+10 \%$ CK.Hasil dari penelitian menunjukan bahwa beton dengan kombinasi (1) $8 \% \mathrm{AT}+14 \% \mathrm{CK}$ memiliki nilai kuat tekan yang tinggi yaitu sebesar $239.36 \mathrm{~kg} / \mathrm{cm} 2$, kenaikan kuat tekannya adalah $6.02 \%$ terhadap beton normal

\section{Berat Volume Beton}

Berat volume beton bergantung pada berat volume agregat, berarti juga bergantung pada jenis agregatnya, apakah berbobot ringan, normal atau berat (untuk pelindung terhadap nuklir). Untuk memahami cara menetapkan nilai berat volume agregat dengan menggunakan alat silinder logam dan bahan agregat dengan ukuran butir lolos saringan dengan ukuran $20 \mathrm{~mm}$ dan tertahan pada saringan no. 4. Agregat adalah sekumpulan butir- butir batu pecah, kerikil, pasir, atau mineral lainnya baik berupa hasil alam maupun buatan (SNI No: 1737-1989-F). Agregat adalah material granular, misalnya pasir, 
kerikil, batu pecah yang dipakai bersamasama dengan suatu media pengikat untuk membentuk suatu beton semen hidraulik atau adukan. Kata agregat dapat dijabarkan dari bentuk bahasa latin grex yang berarti sekumpulan atau sekawanan. Berpijak dari akar kata ini, kita kemudian mendapatkan beberapa makna dari aggregate. Mulanya kata ini menyeruak terutama dalam bidang konstruksi di lingkungan penutur bahasa Inggris mengacu pada bahan-bahan mineral tidak bergerak, misalnya pasir, debu, batu, kerikil, pecahan batu yang bercampur semen, kapur, atau bahan aspal untuk mengikat campuran itu menjadi seperti beton. Ketika kita menghimpun benda atau sesuatu yang terpisah-pisah menjadi satu kesatuan, kita seakan menyusun sebuah gundukan atau tumpukan, di mana ujung tumpukan berasosiasi dengan

pencapaian. Proses pengumpulan inilah yang disebut agregat. Sifat agregat merupakan salah satu faktor penentu kemampuan perkerasan jalan memikul beban lalu lintas dan daya tahan terhadap cuaca.

\section{METODE PENELITIAN}

\section{Waktu dan Tempat Penelitian}

Penelitian ini dilaksanakan selama 1 (satu) tahun yang berlangsung dari bulan April 2020 - April 2021. Penelitian ini dilaksanakan di Laboratorium Fakultas
Teknik Universitas Muhammadiyah Makassar, Kota Makassar, Provinsi Sulawesi Selatan

\section{Bahan dan Alat}

Bahan yang digunakan dalam penelitian ini terdiri dari semen Portland Composit Cement (PCC), agregat halus Sungai Je'ne'berang Gowa, agregat kasar yang berasal dari batu pecah Bili-Bili dan air PDAM dan material limbah abu ampas tebu sebagai substitusi agregat halus berasal dari Pabrik Gula Kabupaten Takalar, Provinsi Sulawesi Selatan. Adapun alat yang digunakan adalah alatalat laboratorium untuk uji karakteristik material, mould untuk mal pembuatan benda uji, mixer concrete untuk mencampur adukan beton, slump test digunakan untuk mengukur kelecakan beton segar, dan mesin uji tekan beton.

\section{Metode Penelitian}

Bahan yang digunakan untuk penelitian harus disiapkan terlebih dahulu, ditentukan kualitas masing- masing bahan susunnya, serta dibuatkan cetakan untuk tempat benda uji yang telah direncanakan. Alat yang digunakan pada penelitian ini sebelumnya telah diperiksa kondisi dan kemampuannya serta telah dikalibrasi terlebih dahulu. Benda uji silinder dibuat dengan cara memasukkan beton segar dari molen ke 
dalam cetakan silinder ukuran $15 \mathrm{~cm}$ x 30 $\mathrm{cm}$ yang telah diolesi minyak pelumas. Pengisian ini dilakukan secara bertahap, yaitu tiap sepertiga bagian dilakukan penumbukan dengan tongkat baja sebanyak \pm 25 kali. Setelah 24 jam, cetakan dibuka kemudian dilakukan perawatan dengan direndam di dalam bak air selama 28 hari. Benda uji beton normal sebanyak 9 sampel dan benda uji yang disubstitusi abu ampas tebu sebanyak 9 sampel. Data diperoleh melalui uji tekan benda uji beton di Laboratorium Fakultas Teknik Universitas Muhammadiyah Makassar dengan menggunakan mesin uji kuat tekan.

Hasil uji tekan beton berupa gaya (P) yang terjadi pada saat benda uji hancur. Berdasarkan data gaya tekan dan luas penampang silinder, maka kuat tekan beton dapat dihitung dengan menggunakan rumus :

$f \mathrm{c}^{\prime}=\mathrm{P} / \mathrm{A}$

dimana $: f c^{\prime}=$ Kuat tekan $\left(\mathrm{kg} / \mathrm{cm}^{2}\right)$

$\mathrm{P}=$ Gaya tekan $(\mathrm{kg})$

$\mathrm{A}=$ Luas penampang kubus $\left(\mathrm{cm}^{2}\right)$

Analisis data dilakukan adalah analisis statistik, digunakan untuk mengetahui rata-rata kuat tekan beton. Selanjutnya dilakukan analisis regersi untuk mendapatkan model degradasi mekanik hubungan temperatur dan kuat tekan beton serta model degradasi fisik hubungan antara jumlah abu ampas tebu dan berat volume beton.

\section{Bagan Alir Penelitian}

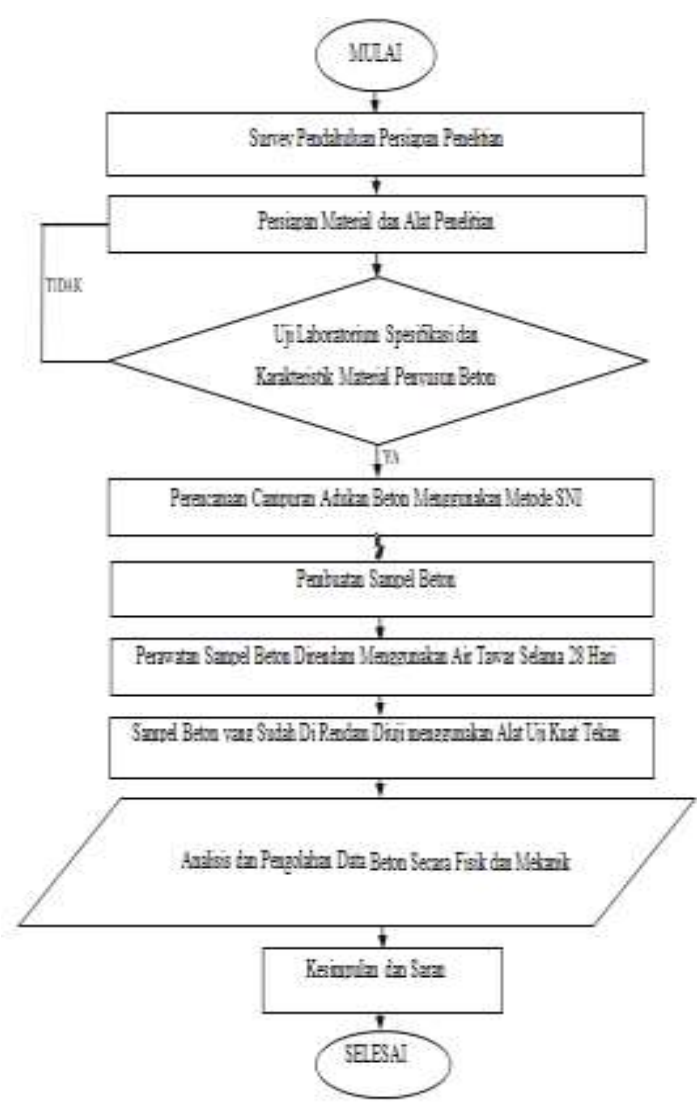

HASIL DAN PEMBAHASAN

Berdasarkan data yang diperoleh dari hasil penelitian yang dilakukan di Laboratorium Fakultas Teknik Universitas Muhammadiyah Makassar dapat dilihat pada gambar 2 . 
Gambar 2. Hubungan Persentase Ampas Tebu dan Berat Volume Beton

Pada gambar 2 yaitu grafik hubungan antara persentase ampas tebu dan berat volome menunjukkan bahwa pada komposisi pencampuran ampas tebu pada $8 \%$ dan $10 \%$ diperoleh berat volume sebesar $701,41 \mathrm{~kg} / \mathrm{m}^{3}$ dan pada komposisi pencampuran $12 \%$ diperoleh berat volume sebesar $690,10 \mathrm{~kg} / \mathrm{m}^{3}$.

\section{KESIMPULAN DAN SARAN}

\section{Kesimpulan}

Berdasarkan dari hasil penelitian dapat disimpulkan bahwa didapatkan nilai berat volume beton untuk komposisi pencampuran ampas tebu $8 \%$ yaitu 701,41 $\mathrm{kg} / \mathrm{m} 3,10 \%$ yaitu $701,41 \mathrm{~kg} / \mathrm{m} 3$ dan $12 \%$ yaitu $690,10 \mathrm{~kg} / \mathrm{m} 3$ dari ketiga komposisi tersebut diperoleh berat volume beton yang maksimal yaitu komposisi pencampuran ampas tebu $12 \%$.

\section{Saran}

Penelitian ini akan kami lanjutkan untuk mengetahui bagaimana pengaruh limbah abu ampas tebu sebagai substitusi parsial pada beton normal secara mekanik.

\section{DAFTAR PUSTAKA}

Adi Wiyono, Adjib Karjanto, Galih Damar Pandulu, 2017, Pengaruh Pengganti Sebagian Semen Dengan Abu Ampas Tebu Terhadap Kualitas Mortar Berdasarkan Kuat Tekan Dan Penyerapan Air, eUREKA : Jurnal Penelitian

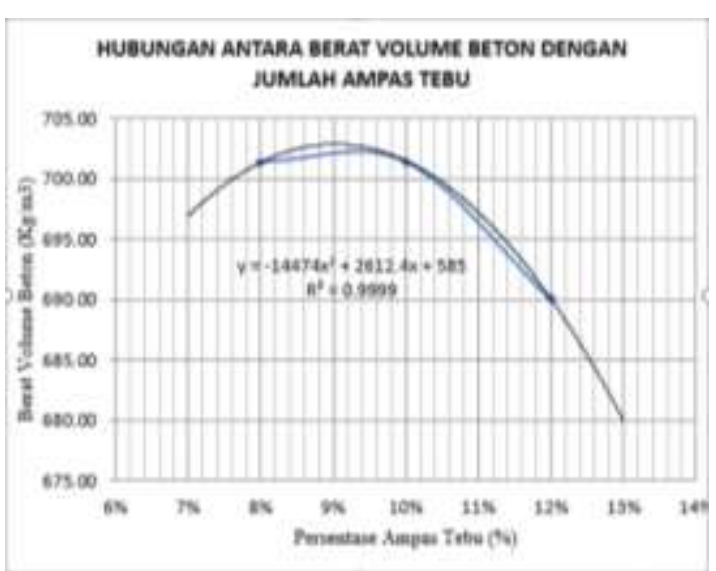

Teknik Sipil dan Teknik Kimia Vol 1, No. 1, e-ISSN 2548-771X (online)

Herri Mahyar, Rizal Syahyadi, Khairul Miswar, 2018, Pengaruh Penambahan Abu Sekam Padidan Abu Ampas Tebu Sebagai Substitusi Semen Terhadap Karakteristik Beton Mutu Tinggi, Proceeding Seminar Nasional Politeknik Negeri Lhokseumawe Vol.2 No.1, ISSN:2598-3954

M. Fahryan Azis, 2020, Pengaruh Penambahan Abu Ampas Tebu Dan Abu Cangkang Sawit Terhadap Kuat Tekan Beton fc 24,9 MPA, Tugas Akhir Sarjana Teknik Pada Program Studi Teknik Sipil, Fakultas Teknik, Universitas Muhammadiyah Palembang

Mamluatul Hasanah, 2018, Perbandingan Berat Isi Dan Rembesan Bata Beton Ringan Dengan Penambahan Material Alami Zeolit Alam Tertahan Saringan No. 80 (0,180mm) Dan Tertahan Saringan No. 200 (0,075mm), Jurusan Teknik Sipil Fakultas Teknik Universitas Brawijaya : Malang

Prabowo Doro Djatun, 2019, Analisa Pengaruh Penambahan Abu Ampas Tebu Pabrik Gula Cinta Manis Ogan Ilir Terhadap Kuat Tekan Beton Pada K-300, Tugas Akhir Sarjana Teknik Pada Jurusan Teknik Sipil, Fakultas Teknik, Universitas Muhammadiyah Palembang

Tisnawati, Dwi Kumalasari, 2019, Pengaruh Penambahan Abu Ampas Tebu Dan Superplasticizer Terhadap Kuat Tekan Beton, Jurnal PENA Vol.33 No.1, E-ISSN-2301$6450 \mid$ 


\section{Jurnal Teknik Hidro}

Vol. 13 No. 2, Agustus 2020

Steven A T M Rajagukguk dan Nursyamsi, 2017, Pengaruh Abu Ampas Tebu Sebagai Bahan Tambah

Sementer hadap Sifat-Sifat Mekanik Beton Dengan Menggunakan Pasir Siantar, http://repositori.usu.ac.id/handle/123456789/1 $\underline{7648}$

Shinta Rahmalia Irawan, 2014, Pemanfaatan Kombinasi Limbah Abu Ampas Tebu Dan Abu Kulit Kerang Sebagai Substitusi Semen Pada Campuran Beton Mutu K225, Jurnal Teknik Sipil dan Lingkungan Vol.2.No.3, ISSN: 2355-374X.

SNI 1974:2011, Cara Uji Kuat Tekan Beton Dengan Benda Uji Silinder, Badan Standardisasi Nasional, Gd. Manggala Wanabakti Blok IV, Lt.3,4,7,10, Diterbitkan Di Jakarta.

SNI-03-3402-1994, Cara Uji Berat Isi Beton Ringan Struktural, Jakarta : Badan Standarisasi Nasional 